\title{
Transitioning the Respiratory Therapy Workforce for 2015 and Beyond
}

\author{
Thomas A Barnes EdD RRT FAARC, Robert M Kacmarek PhD RRT FAARC, \\ Woody V Kageler MD MBA, Michael J Morris MD, \\ and Charles G Durbin Jr MD FAARC
}

\author{
Introduction \\ Methods \\ Results \\ Conference Goal \\ Education \\ Credentials \\ Licensure \\ Transition of Respiratory Therapist Workforce \\ Continuing Education \\ Consortia and Cooperative Models \\ Budgetary Resources \\ Promotion of a Career Ladder \\ American Respiratory Care Foundation \\ Recommendations Not Approved \\ Discussion \\ Education \\ Credentials and Licensure \\ Impact of Change on the Existing Workforce \\ Addressing Workforce Education Issues \\ Summary
}

The American Association for Respiratory Care established a task force in late 2007 to identify likely new roles and responsibilities of respiratory therapists (RTs) in the year 2015 and beyond. A series of 3 conferences was held between 2008 and 2010. The first task force conference affirmed that the healthcare system is in the process of dramatic change, driven by the need to improve health while decreasing costs and improving quality. This will be facilitated by application of evidence-based care, prevention and management of disease, and closely integrated interdisciplinary care teams. The second task force conference identified specific competencies needed to assure safe and effective execution of $\mathrm{RT}$ roles and responsibilities in the future. The third task force conference was charged with creating plans to change the professional education process so that RTs are able to achieve the needed skills, attitudes, and competencies identified in the previous conferences. Transition plans were developed by participants after review and discussion of the outcomes of the first two conferences and 1,011 survey responses from RT department managers and RT education program directors. This is a report of the recommendations of the third task force conference held July 12-14, 2010, on Marco Island, Florida. The participants, who represented groups concerned with RT education, licensure, and practice, proposed, discussed, and accepted that to be successful in the future a baccalaureate degree must be the minimum entry level for respiratory care practice. Also accepted was the recommendation that the Certified Respiratory 
Therapist examination be retired, and instead, passing of the Registered Respiratory Therapist examination will be required for beginning clinical practice. A date of 2020 for achieving these changes was proposed, debated, and accepted. Recommendations were approved requesting resources be provided to help RT education programs, existing RT workforce, and state societies work through the issues raised by these changes. Key words: respiratory care; respiratory therapist; manpower; education; training; competency; licensure; credentialing; accreditation; credentials; specialty; protocols. [Respir Care 2011;56(5):681-690. (C) 2011 Daedalus Enterprises]

\section{Introduction}

In 2007 the American Association for Respiratory Care (AARC) established the "2015 and Beyond" task force. The charge to this task force was to determine the changes required by the profession of respiratory care to meet the evolving demands of the medical community and to position respiratory therapists (RTs) as a vital member of the medical community in 2015 and beyond. ${ }^{1}$ The specific questions the task force was asked to address were:

- How will patients receive healthcare services in the future?

- How will respiratory therapy be provided?

- What knowledge, skills, and attributes will RTs need to provide care safely, efficiently, and cost-effectively?

- What education and credentialing systems are needed to provide this knowledge and these skills and attributes?

- How do we get from the present to the future with minimal impact on the respiratory therapy workforce?

The task force elected to address these questions through a series of 3 conferences. The first conference was held in

\footnotetext{
Thomas A Barnes EdD RRT FAARC is affiliated with the Department of Health Sciences, Northeastern University, Boston, Massachusetts. Robert M Kacmarek PhD RRT FAARC is affiliated with the Department of Anesthesiology, Massachusetts General Hospital, and with Harvard Medical School, Boston, Massachusetts. Woody V Kageler MD MBA is affiliated with the Department of Health Sciences, Tarrant County College, Fort Worth, Texas. Michael J Morris MD is affiliated with the Department of Internal Medicine, Brooke Army Medical Center, San Antonio, Texas. Charles G Durbin Jr MD FAARC is affiliated with the Department of Anesthesiology, University of Virginia, Charlottesville, Virginia.
}

The authors have disclosed no conflicts of interest.

Supplementary material related to this paper is available at http:// www.rcjournal.com

Correspondence: Thomas A Barnes EdD RRT FAARC, Department of Health Sciences, 316 Robinson Hall, Northeastern University, 360 Huntington Avenue, Boston MA 02115-5000. E-mail: t.barnes@ neu.edu.

DOI: $10.4187 /$ respcare. 01169 the spring of 2008. The results of this conference ${ }^{1}$ indicated that the RT of today barely resembles the RTs of the 1950s and 1960s, and the future role of the RT will most likely be different from today. Healthcare is going through dramatic changes, third-party payers are challenging payment for iatrogenic injury, the entire healthcare financial system is being debated, the focus of care is shifting from acute to chronic care, manpower issues are expected to affect all disciplines, the workforce is aging, and rapid introduction of innovation in the provision of medicine and information technology is expected to be the norm. ${ }^{1}$

Conference 2 was held in the spring of 2009. In this conference the attendees focused on identifying the competencies graduate and practicing RTs will need in 2015 and beyond. ${ }^{2}$ The attendees identified 73 competencies in 7 majors areas: diagnostics, disease management, evidencebased medicine and respiratory care protocols, patient assessment, leadership, emergency and critical care, and therapeutics. $^{2}$

See the Related Editorial on Page 720

The third conference of this series was conducted on Marco Island, Florida, July 12-14, 2010. The goal of this conference was to determine what changes in the profession are necessary to position RTs to fulfill the roles and responsibilities identified in conference one and to ensure that future and practicing RTs acquire the competencies identified in conference two. It was postulated that changes would be needed in the RT education, accreditation, and credentialing processes to meet the needs identified from conferences one and two. This paper reports the results and recommendations formulated during the third " 2015 and Beyond" conference.

\section{Methods}

The third conference started with a series of presentations (appendix 1, in the supplementary materials to this paper at http://www.rcjournal.com) designed to facilitate discussion and decision making from the 35 voting participants from 18 stakeholder organizations in attendance (appendix 2). Appendix 3 lists the stakeholder organiza- 


\section{Transitioning the Respiratory Therapy Workforce for 2015 AND Beyond}

tions that were invited to participate in the conference by the "2015 and Beyond" task force. The task force members are listed in appendix 4. Pre-conference surveys of RT program directors, RT department directors, and deans of health science divisions were conducted in May of 2010 by the "2015 and Beyond" research group (appendix 5).

The first day of the conference began with presentations (appendix 1) that reviewed the conclusions and recommendations from the first 2 conferences. ${ }^{1,2}$ These were followed by workforce data from the 2009 AARC Human Resources Study $^{3}$ and presentations of the results of 2 pre-conference surveys, which generated 1,011 responses from RT educators ${ }^{4}$ and directors of respiratory care departments. ${ }^{5}$ The survey questions included the competencies, education level, and credentials needed for entry into practice in 2015 and beyond. Three pre-conference surveys of deans who are members of the Association of Schools of Allied Health Professions, 2-year-college deans without RT programs, and deans with RT programs were not presented because of low response rate. The first conference day ended with an overview of the AARC's Medicare Part B Respiratory Therapy Initiative in the United States Congress.

The second day of the conference focused on generating, discussing, and accepting recommendations for change. We used voting key pads (eInstruction version 5.62.0090, Denton, Texas) to record and display voting on all proposals. A simple majority was used to approve all proposals made by conference attendees, with yes, no, and abstain votes recorded by a computer and the tally projected on the screen at the front of the room following the close of voting. On the third day of the conference, attributes used to evaluate recommendations and 11 recommendations to be forwarded to the AARC Board of Directors were reviewed again by the participants. Post-conference plans for a public hearing, an informational timeline, visits to stakeholder groups, and plans for publication of a conference paper were discussed by the conference participants before the conference adjourned. A public hearing on the recommendations accepted and approved by conference 3 participants was held the day after the conference adjourned.

\section{Results}

The overall goal of the conference was accepted and approved by the attendees. The attributes that transition recommendations needed to meet were approved by conference participants (Table 1). The voting results for recommendations presented and debated can be found in Table 2.

\section{Conference Goal}

The conference goal was to determine what changes in the profession are necessary to position RTs to fulfill the
Table 1. Attributes That 2015 Transition Plans Must Meet

Maintain an adequate number of respiratory therapists throughout the transition.

Address unintended consequences, such as respiratory therapist shortages.

Require multiple options and flexibility in educating both students and the existing workforce. (eg, affiliation agreements, internships, special skills workshops, continuing education)

Require competency documentation options for new graduates.

Support a process of competency documentation for the existing workforce.

Assure that credentialing and licensure recommendations evolve with changes in practice.

Address implications of changes in licensing and credentialing.

Establish practical timelines for recommended actions.

Assure that emerging conference recommendations are supported by a plurality of the stakeholders in attendance.

Reflect the outcomes of the previous two 2015 and Beyond conferences. Identify the agency most appropriate to implement identified elements.

roles and responsibilities identified in conference one and to ensure that future and practicing RTs in 2015 and beyond acquire the competencies identified in conference two.

\section{Education}

A single recommendation regarding $\mathrm{RT}$ education was accepted and approved by majority vote:

- That the AARC request the Commission on Accreditation for Respiratory Care to change, by July 1, 2012, accreditation standard 1.01 to read as follows:

1.01 The sponsoring institution must be a post-secondary academic institution accredited by a regional or national accrediting agency that is recognized by the United States Department of Education and must be authorized under applicable law or other acceptable authority to award graduates of the program a baccalaureate or graduate degree at the completion of the program. Programs accredited prior to 2013 that do not currently offer a baccalaureate or graduate degree must transition to conferring a baccalaureate or graduate degree, which should be awarded by the sponsoring institution, upon all RT students who matriculate into the program after 2020.

\section{Credentials}

Two specific recommendations regarding credentialing were approved:

- That the AARC recommends to the National Board for Respiratory Care (NBRC) on July 1, 2011, that the Certified Respiratory Therapist (CRT) examination be retired after 2014. 


\section{Transitioning the Respiratory Therapy Workforce for 2015 AND Beyond}

Table 2. Votes on Recommendations in the Third Conference

\begin{tabular}{|c|c|c|c|c|}
\hline & $\begin{array}{c}\text { Yes } \\
\text { no. }(\%)\end{array}$ & $\begin{array}{c}\text { No } \\
\text { no. }(\%)\end{array}$ & $\begin{array}{c}\text { Abstain* } \\
\text { no. }\end{array}$ & $\begin{array}{c}\text { Total } \\
\text { no. }\end{array}$ \\
\hline \multicolumn{5}{|l|}{ Approved } \\
\hline Conference goal & $28(88)$ & $4(12)$ & 2 & 34 \\
\hline Evaluation attributes & $26(84)$ & $5(16)$ & 4 & 34 \\
\hline Education & $20(63)$ & $12(38)$ & 3 & 35 \\
\hline Credentials & $25(76)$ & $8(24)$ & 2 & 35 \\
\hline Licensure & $28(93)$ & 2(7) & 5 & 35 \\
\hline Transition of respiratory therapy workforce & $28(90)$ & $3(10)$ & 0 & 31 \\
\hline Continuing education & $31(97)$ & $1(3)$ & 0 & 32 \\
\hline Consortia and cooperative models & $29(100)$ & $0(0)$ & 3 & 32 \\
\hline Budgetary resources & $23(96)$ & $1(4)$ & 7 & 31 \\
\hline Promotion of career ladders & $27(100)$ & $0(0)$ & 4 & 31 \\
\hline American Respiratory Care Foundation & $25(96)$ & $1(4)$ & 4 & 30 \\
\hline \multicolumn{5}{|l|}{ Not Approved } \\
\hline Two levels of practice & $13(41)$ & $19(59)$ & 3 & 35 \\
\hline Licensure recommendation to chartered affiliates & $2(7)$ & $28(93)$ & 5 & 35 \\
\hline Model career pathway & $7(25)$ & $21(75)$ & 6 & 34 \\
\hline
\end{tabular}

- That the AARC recommends to the NBRC on July 1, 2011, that the multiple-choice examination components (CRT and Registered Respiratory Therapist [RRT] written) for the RRT examination should be combined after 2014.

\section{Licensure}

The following licensure recommendation was approved:

- That the AARC establish on July 1, 2011, a commission to assist state regulatory boards transition to the RRT requirement for licensure as an RT.

\section{Transition of Respiratory Therapist Workforce}

A number of recommendations regarding the existing workforce were approved:

- That the AARC Executive Office request that the AARC Board of Directors ask the appropriate existing sections to develop standards to assess competency of RTs in the workforce relative to job assignments of the RT.

- Standards should address the variety of work sites that employ RTs.

- Standards should address RT knowledge, skills, and attributes relative to the tasks being evaluated.

\section{Continuing Education}

The following recommendation regarding continuing education was approved:
- The AARC encourages clinical department educators and state affiliates' continuing-education venues to use clinical simulation as a major tactic for increasing the competency of the current workforce.

\section{Consortia and Cooperative Models}

The following recommendation regarding associate degree programs transitioning to baccalaureate degree programs was approved:

- That the AARC, in cooperation with the Commission on Accreditation for Respiratory Care, consider development of consortia and cooperative models for associate degree programs that wish to align with baccalaureate degree granting institutions for the award of the baccalaureate degree.

\section{Budgetary Resources}

The following recommendation regarding financial resources was approved:

- That the AARC provide budgetary resources to assist associate degree programs with the transition to baccalaureate level RT education.

\section{Promotion of a Career Ladder}

The following recommendation regarding a respiratory therapy career ladder was approved: 


\section{Transitioning the Respiratory Therapy Workforce for 2015 AND Beyond}

- That the AARC Board of Directors explores development and promotion of career ladder education options for the members of the existing workforce to obtain advanced competencies and the baccalaureate degree.

\section{American Respiratory Care Foundation}

The following recommendation regarding the foundation was approved:

- That the AARC request the American Respiratory Care Foundation to establish a restricted fund for donations to support the transition of associate degree programs to baccalaureate level RT education.

\section{Recommendations Not Approved}

The following recommendations considered by the Conference attendees were not approved:

- Two levels of practice, with details to follow.

- That the AARC recommend to chartered affiliates on July 1 , 2011, that they recommend to their state regulatory board: (1) that the RRT credential be required to obtain a license to practice as an RT for all new applicants after 2012, and (2) that a provisional or limited license, effective for 3 years from the date of graduation from an RT program accredited by the Commission on Accreditation for Respiratory Care, be granted to all new applicants after 2012 who have passed the NBRC written registry examination but not the clinical simulation examination.

- That a model career pathway be developed by the AARC with the identified 2015 competencies incorporated into existing program levels but distinguishing between the competencies needed at each level (eg, Registry and Registry PLUS).

\section{Discussion}

\section{Education}

As defined in the results of the second " 2015 and Beyond" conference, ${ }^{2}$ the knowledge, skills, and attributes that future RTs will need exceed those of today's respiratory therapy program graduate. The education requirements of the graduate RT have not changed in 40 years, but the role of the RT has greatly expanded. The RTs of today are expected to perform therapeutic techniques, deliver medications, and operate medical devices that were not even available 20 years ago to evaluate and treat patients with increasingly complex cardiopulmonary disorders. ${ }^{1,6}$ The RT of today is expected to assess and quantify the patient's cardiopulmonary status, to provide appropriate re- spiratory care by applying protocols, and to evaluate the medical and cost effectiveness of the care that RTs deliver. ${ }^{2}$ The expectation is that in 2015 and beyond, in addition to an active role as a bedside care provider, all RTs will be consultants on how respiratory care should be provided. On patient rounds, RTs are expected to contribute to the discussion of goals and direction of therapy and to provide evidence supporting various approaches to respiratory care used in the intensive care unit. Specifically, RTs should possess the ability to discuss and recommend care for patients presenting with diseases that affect the respiratory system. ${ }^{2}$

RTs must achieve higher levels of education and training to respond to these increasing future demands projected by the "2015 and Beyond" task force conferences. ${ }^{7,8}$ The attraction of respiratory therapy as a potential career choice to young people and adults has been partly due to its minimum education standard. The profession's current failure to demand an adequate entry-level education negatively affects the perception of the profession, suggesting a more technical and less professional career. Governmental agencies, legislators, third-party payers, and the military services all use the baccalaureate degree as the minimum education level that differentiates professions from technician groups. ${ }^{9-11}$

Educators are constantly challenged to expand their curriculums to prepare students for these new responsibilities. ${ }^{12,13}$ These demands on RT curriculums will only increase in the future and will have a substantial impact on the education system. Associate degree RT programs are already stretched too thin to teach the knowledge, skills, and attributes that students need to enter the workforce today, let alone those needed in 2015 and beyond. In the pre-conference survey, 165 (47\%) of the RT program directors indicated that because of state and institutional credit constraints for degree completion, they could not increase the credit hours in their curriculum. For example, the Texas Higher Education Coordinating Board restricts associate-degree RT programs to 72 semester hours of credit. ${ }^{14}$ In the pre-conference survey of deans and directors of health science divisions with accredited RT programs, only $21(30 \%)$ said that baccalaureate RT degree should be required for entry into the profession. ${ }^{15}$ However, $46(67 \%)$ of those respondents stated that a baccalaureate should be required after licensure for continued practice. The results of this survey lack validity because of the low response rate of $18 \%$ (75 of 411 colleges). The increased knowledge, new skills, and professional attributes simply cannot be easily taught in an already crowded 2 -year curriculum. As medical science advances, it will be increasingly difficult for RT educators to add additional material to their curriculum. Too few associate-degree RT programs teach their students how to read and critique research, understand the statistical data, and search for evidence to support respiratory care practice. Evidence- 


\section{Transitioning the Respiratory Therapy Workforce for 2015 AND Beyond}

based medicine has become the standard for practice of all professions, and the graduate RTs must be proficient in the tenets of evidence-based medicine today and certainly by 2015 and beyond. ${ }^{13}$

The 2015 research group survey of RT program directors shows that evidence-based medicine and protocols, and leadership skills are not currently taught by the majority of associate-degree RT programs nor mastered by graduates. ${ }^{4}$ Only $34 \%$ of associate-degree RT programs teach their students about evidence-based medicine and protocols, compared to $78 \%$ of baccalaureate RT programs. ${ }^{4}$ The survey showed that $80 \%$ of baccalaureate RT programs teach students how to understand and critique published research, a necessary skill to practice evidence-based medicine, compared to $41 \%$ of associate-degree RT program. ${ }^{4}$ Only one third of associate-degree RT programs teach students the meaning of general statistical tests, compared to over $78 \%$ of baccalaureate RT programs.

Changes in healthcare policy, regulation, and reimbursements have required RTs to adopt expanded roles, work more independently in settings across the continuum of care, and collaborate as partners in the healthcare delivery team. Sixty-three percent of baccalaureate RT programs teach students how to lead groups in care planning and facilitate collaboration, compared to only $52 \%$ of associate-degree RT programs. ${ }^{4}$ Other areas where leadership is taught more often by baccalaureate RT programs than associate-degree RT programs are regulatory requirements of the healthcare system, financial reimbursement, and contributing to organizational teams for planning and collaborative decision making. ${ }^{4}$

Many associate-degree RT programs have had to increase from 2 years to 3 years to meet current needs and to prepare students to pass the CRT and RRT examinations. ${ }^{4}$ Add a fourth year to a three-year associate-degree RT program and the student qualifies for a baccalaureate RT degree in many institutions. Requiring 3 years of coursework and only awarding an associate degree is grossly unfair to the student in these expanded associate degree programs. ${ }^{4}$

The "2015 and Beyond" conference 3 recommendations include a transition period of 10 years for associate-degree RT programs to make the arrangements necessary to be able to award baccalaureate RT degrees. Several senior colleges and universities have consortia agreements to award the baccalaureate degree in respiratory therapy to accredited baccalaureate RT programs located in academic medical centers and community colleges. Further, several accredited baccalaureate RT programs have online curriculums for associate degree RT students to complete requirements for a baccalaureate RT degree. These are proven methods for awarding a baccalaureate degree when the parent institution does not have baccalaureate degree granting authority. In addition, some community colleges are able to award baccalaureate degrees. ${ }^{16-18}$
Three conference recommendations were made to help associate-degree RT programs transition over 10 years to award a baccalaureate degree or higher in respiratory therapy. Development of consortia and cooperative models was recommended, because many currently accredited registry-eligible programs use this method to award baccalaureate degrees to their graduates. This recommendation is important because it is designed to show with timetested models how associate degree RT programs, baccalaureate RT programs, and senior colleges can work together to reach a minimum baccalaureate degree entry level by 2020. Conference participants also requested that the AARC and the American Respiratory Care Foundation provide financial resources to help associate-degree RT programs transition to the point where they can award baccalaureate degrees directly or with a consortium agreement with a baccalaureate RT program or senior college. The AARC was requested by conference participants to ask the American Respiratory Care Foundation to establish a restricted fund for donations to help finance the transition of associate degree RT to baccalaureate RT programs.

The "2015 and Beyond" conference 3 heard pro and con arguments on the recommendation for transitioning to a baccalaureate RT degree entry level by 2020 . Participants had no authority to vote on behalf of their respective agencies. The opposition position to change in education level is discussed below.

The RT profession has grown substantially over the past 50 years. ${ }^{1}$ Its growth corresponds to an ever-increasing body of knowledge and technology, along with the skills required to serve patients in various settings. ${ }^{1}$ However, the recommendation approved by the majority of attendees at conference 3 may not be feasible for many of the currently accredited RT programs. While all 3 "2015 and Beyond" conferences explored numerous issues related to increasing the RT education requirement to the baccalaureate level, they failed to discuss important aspects of the transition that could limit successful implementation:

- Transitioning from associate degree to baccalaureate degree by a secondary institution is politically charged and not likely to occur. Our nation's community colleges have played a major role in educating the respiratory care workforce. Currently there are $356(87 \%)$ community college RT programs that award an associate degree, and their approximate enrollment is 6,230 RT students. Fifty-five programs (13\%) award a baccalaureate RT degree, and most of these programs are at 4-year colleges. ${ }^{3,4}$ While many current program directors may be interested in pursuing additional education opportunities for their students, there is no analysis that shows that 4-year institutions are willing to engage the transition and education of the respiratory care workforce from community colleges. Many 4-year colleges might be re- 


\section{Transitioning the Respiratory Therapy Workforce for 2015 AND Beyond}

luctant to invest in this workforce program if the return on investment is not profitable. In the states that allow baccalaureate degrees to be offered only in specified 4-year institutions, the current 2-year RT programs in community colleges would need to transition to this new standard. Additionally, due to force structure and degree requirements for its officers and enlisted corps, the current military programs are unlikely to be able to make the transition. Despite the fact that feasibility was accepted as an important attribute for any transition plan, this conference failed to assess the likelihood or cost involved in converting current 2-year programs or establishing new baccalaureate programs.

- The necessity of baccalaureate degree to maintain an entry level qualified workforce is disputed. The goal of the 3 conferences was to discuss the attributes for the future graduate RT, recommend competencies for future RTs, and identify the education pathway needed to reach this goal. However, there is a clear difference between recommended competencies and the required education level. Many of the competencies needed in 2015 and beyond are currently being taught in associate-degree RT programs, and additional education is not absolutely required for trained and competent RTs. There currently are numerous additional career pathways with additional skills for RTs to pursue that are recognized in the absence of a baccalaureate RT degree, including the Pulmonary Function Technologist, Neonatal/Pediatric Respiratory Care Specialist, and Certified Sleep Disorders Specialist. These specialties require additional education and on-the-job training, which is specialized training and not expected of the graduate RT. There is minimal and insufficient evidence that RTs with baccalaureate degrees are more prepared to enter the workforce than RTs with associate degrees, to undertake such a largescale restructuring of the respiratory care education system.

- Increased competency based on increased education level is not proven. Current evidence does not suggest that additional education leads to a more qualified or competent RT. The NBRC study Effects from Education Program Type on RRT Candidate Outcomes demonstrated interesting characteristics of education level compared to pass rates on the CRT and RRT examinations. ${ }^{19}$ Candidates who had earned a baccalaureate RT degree had a pass rate of $87 \%$ on the CRT, whereas associate degree holders had a pass rate of $79 \%$. Candidates with a baccalaureate RT degree had a pass rate of $73 \%$ on the RRT, whereas those with an associate degree had a pass rate of $68 \%$. Increasing the education level does not result in such large improvement in the examination pass rate. Before undertaking this transition, further consideration should be given to alternatives that will achieve the desired outcome: RTs who are prepared to be tomorrow's workforce. Examples of alternatives include:

- Encouraging programs to affiliate with a 4-year college to allow students to continue with studies for a baccalaureate degree after earning an associate degree.

- Continuing to support specialty certification that allows students to continue their education, with a focus on the needs for their specific job duties.

- Developing an internship model through healthcare facilities, with a structured curriculum that allows the RT to take specialty examinations.

\section{Credentials and Licensure}

Graduate RTs are currently required to take 3 examinations to become an RRT. ${ }^{2}$ First they must pass the CRT examination and be recognized as a Certified Respiratory Therapist. This examination is also used by most states as the state licensure examination. Upon successful completion of the CRT examination, the graduate RT is expected to take the RRT examination. The RRT examination is taken in 2 parts: a written multiple-choice examination, followed by a clinical simulation examination. While most graduates of RT programs take the CRT examination, a smaller percentage take the RRT examination. The current 2-tier credentialing system and state laws that require successful completion of only the CRT examination for licensure offer insufficient incentives to graduating RTs to demonstrate competency in areas tested by the RRT examinations. In 2003 the AARC, the Commission on Accreditation for Respiratory Care, and the NBRC recognized the RRT credential as the "standard of excellence" for RTs.

Both of the "2015 and Beyond" conference 3 recommendations on the appropriate credential to enter practice in 2015 stem from the widely held view that there is no difference in job duties between those holding the CRT and RRT credentials. In the pre-conference survey, RRT was selected over CRT as the credential that future graduates should earn to enter the profession by $81 \%$ of the RT department directors 5 and $68 \%$ of the directors of accredited RT programs. ${ }^{4}$ A majority of the conference 3 participants believe that the scope of practice in 2015 will require the level of knowledge and critical thinking tested by the RRT examination. They were confident that the knowledge, skills, and attributes tested on the CRT examination, but not currently on the RRT examination, could easily be incorporated into the two RRT examinations. The vast majority felt that educators are now preparing students for the RRT examinations and that 2015 is the right time to require the RRT credential for entry into practice. The same question asked in the pre-conference survey ${ }^{15}$ of deans and directors of health science divisions with ac- 


\section{Transitioning the Respiratory Therapy Workforce for 2015 AND Beyond}

credited RT programs found that 50 respondents $(75 \%)$ favored the RRT being required to enter practice as an RT. In another pre-conference survey, of members of the Association of Schools of Allied Health Professions, 13 respondents $(81 \%)$ indicated a baccalaureate or graduate degree should be required of RTs for licensure. ${ }^{20}$ (Both of these surveys of deans had low response rates: $18 \%$ and 13\%, respectively.) By 2015 the graduate RT must enter the profession demonstrating the confidence and skills required for practice at the registry level. ${ }^{2}$ The American public should feel assured that patient care is given by the most competent and highly trained RT possible. Many RT educators and department directors surveyed prior to the conference stated that having 2 credentials (CRT and RRT) confuses the public, patients, and other healthcare colleagues who are not aware of the difference, primarily because CRTs and RRTs are assigned the same job responsibilities. The majority of conference participants believe that the respiratory therapy profession needs one level of credential (RRT), one education goal, and one expectation for competency of graduate RTs entering the workforce in 2015 and beyond. Of great concern to conference participants was the fact that the CRT credential was developed for 12-month training programs that will no longer exist in 2015. Any change in the credentialing system may require changes in some state regulations controlling who may deliver respiratory care.

Participants at the conference recognized the need to prepare for changes in state legislation and regulations regarding licensure of RTs to practice if the CRT examination is retired. Accordingly, the conference recommended that the AARC establish on July 1, 2011, a commission to assist state regulatory board transition to an RRT license. Many state licensure regulations currently state that the CRT or RRT is required for a license to practice. This type of regulatory language will accommodate grandfathered RTs with the CRT credential and also be able to license RRTs without the CRT credential. ${ }^{21}$ Currently, the reference to the "entry level exam" means the CRT examination (but in most cases does not actually state it is the CRT examination, but simply the "entry level exam"). If the entry level were to become the RRT, most laws would not have to be amended. Most boards have fairly flexible regulatory authority and could shift over to the RRT exam if that were to become the entry level (including, presumably, some type of grandfather provision). ${ }^{21}$ The purpose of the recommended AARC Licensure Commission is to develop models of regulatory language and to work with state licensure boards to make the transition needed by 2015 .

\section{Impact of Change on the Existing Workforce}

As the expectations of the respiratory care entry level workforce change, increasing pressure will develop to as- sist existing practitioners to meet these new standards by documenting their success at acquiring the new competencies. Additional pressure will come from state licensing boards, and the public will demand that all healthcare professionals maintain evidence of continued basic competence throughout their professional careers. Time-limited medical specialty certification with required periodic recertification is now the standard for physicians and other professionals. While individuals already in the workforce are likely to be grandfathered, employers and the public will probably demand evidence of continued competence of all healthcare workers. ${ }^{22}$

Professional development, life-long learning, and validation of continued competence are the responsibility of each individual practitioner. A profession has a duty to define what its professionals should know and how they should act, and then provide continued education and documentation tools for its members to achieve those goals. This has traditionally been achieved in the form of scientific meetings, publications, and workshops, with or without an examination or certificate to demonstrate acquisition of the new knowledge. However, professional success depends on more than just knowledge: it requires acquiring new skills, new attitudes, and applying new knowledge to daily clinical practice. Employers are required to teach, test, and certify clinical competency with regard to required tasks of a particular job. The AARC should establish practice standards that include knowledge, skills, attitudes, judgment, abilities, experience, and ethics. The AARC should foster the development of tools to assess competence in all these areas throughout the duration of an RT's career. Clinical simulation techniques are useful for both teaching and assessing successful acquisition of new knowledge, skills, and attitudes in moving the current workforce members into the workforce of the future. Acceptance of the conference recommendation to elevate the entry level for RT practice to RRT will require individuals to achieve a higher level of problem-solving skills and pass a more comprehensive examination of clinical reasoning before entering into practice. Elimination of the current 3-examination system (also a recommendation of this third conference) will go a long way toward changing the expectations placed on students as they begin their education program, and will result in a different performance of successful program graduates throughout their professional careers.

\section{Addressing Workforce Education Issues}

The conference participants recommended that the AARC Executive Office and Board of Directors ask existing specialty sections to develop standards to assess and increase competency of RTs in the workforce relative to job assignments. The precedence of experienced RTs work- 


\section{Transitioning the Respiratory Therapy Workforce for 2015 AND Beyond}

Table 3. Recommendation Time Lines for Major Policy Changes and Effective Dates for Implementation

\begin{tabular}{lcc}
\hline \hline Recommendation & $\begin{array}{c}\text { Change } \\
\text { Timeline }\end{array}$ & $\begin{array}{c}\text { Effective } \\
\text { Date }\end{array}$ \\
\hline $\begin{array}{l}\text { Change Commission on Accreditation for Respiratory Care accreditation standard to require } \\
\text { new programs after 2012 to offer a baccalaureate degree in respiratory therapy }\end{array}$ & July 1, 2012 \\
$\begin{array}{l}\text { Change Commission on Accreditation for Respiratory Care accreditation standard to require } \\
\text { all accredited programs after 2020 to offer a baccalaureate degree in respiratory therapy }\end{array}$ & July 1, 2012 \\
$\begin{array}{l}\text { Retire National Board for Respiratory Care Certified Respiratory Therapist examination } \\
\text { after 2014 }\end{array}$ & July 1, 2011 January 1, 2021 \\
\hline
\end{tabular}

ing in specialized areas such as neonatology and pediatrics, pulmonary function technology, sleep disorders, diagnostics, ground and air transport, long-term care, adult acute care, management, and education is well established. ${ }^{2}$ Competency standards should address the variety of work sites that employ RTs and delineate the knowledge, skills, and attributes relative to the tasks needed in each specialty area.

Participants attending the conference requested that the AARC Board of Directors explore development and promotion of career ladder education options for the members of the existing workforce to obtain advanced competencies and the baccalaureate degree. This stems from the finding of the first conference that the roles and responsibilities of the RT workforce will change substantially in the near future, in response to major changes in the United States healthcare system. ${ }^{1,2}$ The AARC must develop options for the current RT workforce to prepare for the new roles and responsibilities in 2015 and beyond. Further education and training in each of the 7 competency areas identified by the 2015 conference and in all the specialty areas need to begin immediately for the profession to ready by $2015 .^{1,2}$

In the current and future education of RTs, the use of simulation undoubtedly will need to increase significantly. There are numerous capabilities, both in computer and human simulation, that may play a valuable role in RT education. One challenge in increasing the education requirement to the baccalaureate level may be in providing additional training opportunities. While the experience of direct patient care cannot be replaced, valuable knowledge and practice can be gained in the safety of the simulation environment. Many of the current capabilities of simulation were explored in "Respiratory System Simulations and Modeling." 23 MacIntyre categorized the simulation assets as: computerized simulation of patient signs and symptoms; computerized anatomic simulation and modeling of the respiratory system; and computerized physiologic simulation and modeling. Patient simulation systems include the full-size human patient simulator (to include ventilators) with modeling of upper-airway anatomy, breath sounds, respiratory system mechanics, and gas exchange. Airway simulation and modeling includes bronchoscopy simulation and 3-dimensional virtual bronchoscopy. Phys- iologic simulation and modeling can include respiratory system mechanics, distribution of ventilation, and gas exchange. Continued advances in this simulation technology can be directly applied to education of providers of mechanical ventilation. ${ }^{24}$

Simulation is already an effective clinical tool to train RTs and other medical providers in multiple clinical scenarios. The most frequent application has been in teaching basic resuscitation skills where use of human patient simulators is extensive and is shown to be superior to traditional teaching methods. ${ }^{25}$ The use of mechanical ventilation simulators with medical residents for treatment of acute respiratory distress syndrome (ARDS) has demonstrated improvement in selecting proper ventilator settings. ${ }^{26}$ Other specific respiratory therapy techniques, such as mini-bronchoalveolar lavage, are likewise effectively taught via simulation. ${ }^{27}$ Preparation of the RT for work in the intensive care unit can be accomplished safely and effectively, and provide immediate feedback for individuals or a team, and clearly should be an integral part of any RT curriculum. ${ }^{28}$ The value of simulation has been demonstrated in many different scenarios, such as trauma and the intensive care unit. ${ }^{29}$ Given the current variety of simulation platforms and the expanding education needs of future RTs, simulation in didactic and clinical scenarios will be invaluable.

\section{Summary}

In response to major changes evolving in the United States healthcare system, the role and responsibilities of the RT workforce will change substantially. As predicted in the first conference, there will be increasing pressure for improved quality, reduced cost, and higher expectations of healthcare professionals. The second " 2015 and Beyond" conference reached general agreement on entry-level competencies graduate RTs will need to succeed in this emerging healthcare environment. This third conference reached majority agreement on the need for a baccalaureate degree as the minimum entry education level and the RRT as the credential for beginning respiratory care practice. Discussion about how such changes would affect current program accreditation and migration, licensure, and the ex- 


\section{Transitioning the Respiratory Therapy Workforce for 2015 AND Beyond}

isting workforce led to recommendations that the AARC commit resources to support individuals and organizations in overcoming these challenges. Timelines (Table 3) to achieve these needed changes were proposed and accepted by a majority of the participants in this conference.

\section{REFERENCES}

1. Kacmarek RM, Durbin CG, Barnes TA, Kageler WV, Walton JR, O'Neil EH. Creating a vision for respiratory care in 2015 and beyond. Respir Care 2009;54(3):375-389.

2. Barnes TA, Gale DD, Kacmarek RM, Kageler WV. Competencies needed by graduate respiratory therapists in 2015 and beyond. Respir Care 2010;55(5):601-616.

3. American Association for Respiratory Care. AARC 2009 respiratory therapist human resource study. Irving, Texas: AARC; June 2009.

4. American Association for Respiratory Care. AARC 2015 Research Group. Survey of respiratory therapy program directors. Irving, Texas: AARC; June 2010

5. American Association for Respiratory Care. AARC 2015 Research Group. Survey of respiratory care department directors. Irving, Texas: AARC; June 2010

6. Stoller JK, Niewoehner DE, Fan VS. Disease management as an evolving role for respiratory therapists. Respir Care 2006;51(12): 1400-1402.

7. Barnes TA. Improving survival from in-hospital cardiac arrest. Respir Care 2010;55(8):1100-1102.

8. American Association for Respiratory Care. A white paper from the AARC Steering Committee of the Coalition For Baccalaureate and Graduate Respiratory Therapy Education: development of baccalaureate and graduate degrees in Respiratory Care. Irving, Texas: AARC; 2003. http://www.aarc.org/resources/bacc_edu/index.asp. Accessed March 10, 2011.

9. US Public Health Service, Commissioned Corps. Requirements: profession: therapist. Updated January 4, 2010. http://www.usphs.gov/ profession/therapist/requirements.aspx. Accessed March 10, 2011.

10. United States Office of Personnel Management. Federal employment information facts sheets: qualification requirements for federal jobs. Updated January 15, 2010. http://www.usajobs.gov/ei/ qualificationrequirements.asp. Accessed March 10, 2011.

11. American Association for Respiratory Care. In the news: Medicare respiratory therapy initiative: frequently asked questions. September 2, 2010. http://www.aarc.org/headlines/09/02/faq.cfm. Accessed March 10, 2011.

12. Goodfellow LT. Respiratory therapists and critical-thinking behaviors: a self-assessment. J Allied Health 2001;30(1):20-25.

13. Hess DR. What is evidence-based medicine and why should I care? Respir Care 2004;49(7):730-741

14. Texas Higher Education Coordinating Board. Guidelines for instructional programs in workforce education. June 2010. http://www.thecb. state.tx.us/aar/undergraduateed/workforceed/gipwe2010/gipwe2010 pdf. Accessed March 10, 2011.

15. American Association for Respiratory Care. 2015 Research Group. Survey of deans and directors of health science divisions with accredited respiratory therapy programs. Irving, Texas: AARC; May 2010

16. Moltz D. Not just a foot in the door. Inside Higher Ed. August 12, 2010 http://www.insidehighered.com/news/2010/08/12/baccalaureate. Accessed March 10, 2011.

17. The Higher Learning Commission North Central Association of Colleges and Schools. Baccalaureate education in the community college setting: task force executive summary with recommendations. Chicago; February 23, 2001

18. DL Floyd MS, KP Walker. The community college baccalaureate: emerging trends and policy issues. Sterling, Virginia: Stylus Publishers; 2005.

19. Shaw RC, Traynor C. Effects from education program type on RRT candidate outcomes. Olathe, Kansas: National Board for Respiratory Care; 2010.

20. American Association for Respiratory Care. 2015 Research Group. Survey of members of the Association of Schools of Allied Health Professions. Irving, Texas: AARC; May 2010.

21. West C. State entry level testing requirements for respiratory therapy licensure. Irving, Texas: AARC; 2008.

22. Citizen Advocacy Center. Maintaining and improving health professional competence: road map to continuing competency assurance. Washington DC; 2004

23. MacIntyre NR. Respiratory system simulations and modeling. Respir Care 2004;49(4):401-408; discussion 408-409.

24. Wax RS, Kenny L, Burns P. Educating providers of mechanical ventilation: an update. Curr Opin Crit Care 2006;12(1):61-66.

25. Wayne DB, Didwania A, Feinglass J, Fudala MJ, Barsuk JH, McGaghie WC. Simulation-based education improves quality of care during cardiac arrest team responses at an academic teaching hospital: a case-control study. Chest 2008;133(1):56-61.

26. Cox CE, Carson SS, Ely EW, Govert JA, Garrett JM, Brower RG, et al. Effectiveness of medical resident education in mechanical ventilation. Am J Respir Crit Care Med 2003;167(1):32-38.

27. Tuttle RP, Cohen MH, Augustine AJ, Novotny DF, Delgado E, Dongilli TA, et al. Utilizing simulation technology for competency skills assessment and a comparison of traditional methods of training to simulation-based training. Respir Care 2007;52(3):263-270.

28. Grenvik A, Schaefer JJ, 3rd, DeVita MA, Rogers P. New aspects on critical care medicine training. Curr Opin Crit Care 2004;10(4):233237.

29. King DR, Patel MB, Feinstein AJ, Earle SA, Topp RF, Proctor KG Simulation training for a mass casualty incident: two-year experience at the Army Trauma Training Center. J Trauma 2006;61(4): 943-948. 